\title{
An updated Simpson-Based Method for Chatter Stability Prediction in Milling
}

\section{Zhenghu Yan}

Xi'an Technological University

Changfu Zhang ( $\nabla$ wzhangcf@163.com )

Xi'an Technological University

Jianli Jia

Xi'an Technological University

\section{Baoji Ma}

Xi'an Technological University

\section{Xinguang Jiang}

Xi'an Technological University

Dong Wang

Xi'an Technological University

\section{Wei Wang}

Xi'an Technological University

\section{Chenxi Yang}

Xi'an Technological University

\section{Research Article}

Keywords: Simpson-based method, Chatter stability, Milling, Convergence rate, Computation time

Posted Date: August 19th, 2021

DOl: https://doi.org/10.21203/rs.3.rs-811142/v1

License: (c) (1) This work is licensed under a Creative Commons Attribution 4.0 International License.

Read Full License 


\title{
An updated Simpson-based method for chatter stability prediction in
}

\author{
milling \\ Zhenghu Yan, Changfu Zhang*, Jianli Jia, Baoji Ma, Xinguang Jiang, Dong Wang, \\ Wei Wang, Chenxi Yang \\ School of Mechatronic Engineering, Xi'an Technological University, Xi'an 710021, \\ China
}

Corresponding author: Changfu Zhang

E-mail: cfzhang@xatu.edu.cn

Tel./Fax.: +86- 10-8617-3309/+86- 10-8617-3309

\begin{abstract}
An updated Simpson-based method (USBM) is presented for milling stability analysis. Firstly, the delay differential equation (DDE) is employed to describe the milling process mathematically. Then, the tooth passing period is divided into two subintervals, i.e., the free and forced vibration intervals. Only the forced vibration interval is divided into many equal small-time intervals. Subsequently, the DDE in the state space is solved based on direct integration. By combining the two-step Simpson method and the semi-discretization method, the state transition matrix of the milling system is constructed. The comparison of convergence rate is conducted to validate the accuracy of the proposed method. The results show that the proposed method converges faster than the benchmark methods. The stability lobe diagrams for the one degree of freedom (one-DOF) and two degrees of freedom (two-DOF) milling systems are also obtained by different methods for further evaluation. Meanwhile, the computation time analysis is also carried out. It is revealed that the proposed USBM has advantages in both accuracy and efficiency. Besides, the proposed method can accurately and efficiently predict the stability of milling with both large and low immersion conditions.
\end{abstract}

Keywords: Simpson-based method; Chatter stability; Milling; Convergence rate; Computation time

\section{Introduction}

Milling operation is an effective processing technology, which is suitable for the machining of workpieces with various complex shapes. Regenerative chatter, which harms surface quality and productivity, is easy to initiate in the milling process. Moreover, chatter increases the cutting forces and may chip the tool and produce a poor, wavy surface finish [1]. Therefore, avoiding chatter is crucial to ensure the high surface finish with high material removal rate. The stability lobe diagram, which divides the parameter plane of spindle speed and axial depth of cut into stable and unstable regions, can be used to select chatter-free parameters. The process parameter combinations in the stable region can be used to avoid chatter and achieve high 
productivity. Therefore, the demand for developing accurate and efficient milling stability prediction methods is increasing.

The delay differential equation (DDE) is usually used to describe the milling process mathematically. By solving the DDE, the milling stability prediction methods can be derived. Up to now, extensive stability prediction methods in milling have been proposed. Altintas and Budak [2] presented a well-known and efficient zeroth-order approximation (ZOA) method. In this method, the DDE is transformed into the frequency domain by Laplace transform. Science the axial depth of cut is expressed analytically, the computational efficiency of the ZOA method is high. Considering that only a single harmonic of the tooth passing period is considered during the approximation of directional coefficients, the prediction accuracy of the ZOA method is not high at low immersion milling. After that, Merdol and Altintas [3] extended the ZOA method and proposed a multi-frequency method. Since high-order harmonics of the tooth passing period are used to approximate the directional coefficients, the multi-frequency method can accurately predict the stability at low immersion milling. In addition, the ZOA method is also extended for the analysis of stability in milling with non-uniform cutters [4-6].

The ZOA method and multi-frequency method are frequency-domain methods. Many time-domain methods have also been reported. Bayly et al. [7] presented a temporal finite element analysis method, and Butcher et al. [8] proposed a Chebyshev collocation method. Insperger et al. presented the semi-discretization method (SDM) [9], the updated SDM [10], and the first-order SDM (1st SDM) [11]. The SDMs proposed by Insperger et al. are time-consuming methods. To improve the computational efficiency, Ding et al. [12] developed a full-discretization method (FDM), which is proved to be more efficient than the SDM. Then, the second-order FDM (2nd FDM) [13], the third-order FDM (3rd FDM) [14], and the hyper-third-order FDMs [15] were proposed one after another. The comparative study shows that the prediction accuracy reaches the highest when the order of the full-discretization method is four. In the framework of FDM, extensive methods [16-28] have been proposed to explore the method with both high prediction accuracy and high computational efficiency. In recent years, Jiang et al. [29] developed a second-order SDM (2nd SDM), in which the delayed term is approximated by second-order Newton interpolation polynomial. In this method, the precise time-integration (PTI) algorithm is used to improve computational efficiency. Liu et al. [30] suggested an improved semi-discretization method based on the predictor-corrector scheme (PCSDM) for milling stability analysis. Besides, many other time-domain methods have also been suggested to predict the stability of milling. Ding et al. [31] reported the numerical integration method (NIM) based on the integral equation and numerical integration formulas. Dong et al. [32] developed an updated numerical integration method (UNIM) based on the NIM. Li et al. [33] presented a complete discretization scheme (CDS). In the CSD, the differential term of the DDE is discretized using Euler's method. Inspired by the CSD, Xie et al. [34] proposed an improved complete discretization method. Niu et al. [35] recommended two Runge-Kutta-based methods, namely the classical fourth-order Runge-Kutta 
method (CRKM) and the generalized form of the Runge-Kutta method (GRKM). The GRKM is proved to converge faster than the CRKM. Li et al. [36] suggested a Runge-Kutta-based complete discretization method (RKCDM) by combining the CRKM and the CDS. Dai et al. [37] presented a milling stability prediction method using the precise integration method. By approximating the differential term of the DDE, several methods were proposed for milling stability analysis, such as the differential quadrature method [38], the numerical differentiation method [39], and the Chebyshev-wavelet-based method [40]. Based on the numerical solution of ordinary differential equations, Qin et al. presented the Adams-Moulton-based method (AMM) [41] and the Adams-Simpson-based method (ASM) [42]. The ASM is proved to be more accurate than the AMM.

The Simpson-based method (SBM) suggested by Zhang et al. [43] achieves satisfactory accuracy and efficiency. In this work, we attempt to propose an updated Simpson-based method by combining the two-step Simpson method and the SDM to improve accuracy and efficiency further. The framework of this paper is as follows: Section 2 illustrates the Mathematical model of milling. Section 3 shows the derivation process of the proposed method. Section 4 gives the comparison and discussion. In this section, the proposed method is validated from the aspect of convergence rate and computational time. The main conclusions are given in Section 5 .

\section{Mathematical model of milling}

The milling process considering regenerative effect can be described by the following equation

$$
\mathbf{M q}(t)+\mathbf{C} \mathbf{q}(t)+\mathbf{K q}(t)=-a_{p} \mathbf{K}_{c}(t)[\mathbf{q}(t)-\mathbf{q}(t-T)]
$$

where $\mathbf{M}, \mathbf{C}$, and $\mathbf{K}$ denote the modal mass, damping, and stuffiness matrices, $a_{p}$ represents the axial depth of cut, $\mathbf{q}(t)$ represents the displacement vector, and $\mathbf{K}_{c}(t)$ is the directional cutting force coefficients matrix. $T$ is the time delay which equals the tooth passing period, i.e., $T=60 /(N \Omega)$, where $N$ is the number of cutter teeth, and $\Omega$ is the spindle speed in rpm.

$$
\begin{aligned}
& \text { Let } \mathbf{U}(t)=\left[\begin{array}{l}
\mathbf{q}(t) \\
\boldsymbol{q}(t)
\end{array}\right] \text {, Eq (1) can be re-expressed as } \\
& \boldsymbol{\mho}(t)=\mathbf{A}(t) \mathbf{U}(t)+\mathbf{B}(t) \mathbf{U}(t-T)
\end{aligned}
$$

where

$$
\mathbf{A}(t)=\mathbf{A}_{0}-\mathbf{B}(t)
$$

and

$$
\mathbf{A}_{0}=\left(\begin{array}{cc}
0 & \mathbf{I} \\
-\mathbf{M}^{-1} \mathbf{K} & -\mathbf{M}^{-1} \mathbf{C}
\end{array}\right)
$$




$$
\mathbf{B}(t)=\left(\begin{array}{cc}
0 & 0 \\
a_{p} \mathbf{M}^{-1} \mathbf{K}_{c} & 0
\end{array}\right)
$$

For a one-DOF milling system only considering a single dominant structural mode in the $X$ direction, the matrices $\mathbf{A}_{0}$ and $\mathbf{B}(t)$ can be given as

$$
\begin{gathered}
\mathbf{A}_{0}=\left[\begin{array}{cc}
0 & 1 \\
-\omega_{n x}^{2} & -2 \zeta_{x} \omega_{n x}
\end{array}\right] \\
\mathbf{B}(t)=\left[\begin{array}{cc}
0 & 0 \\
\frac{a_{p} h_{x x}(t)}{m_{x}} & 0
\end{array}\right]
\end{gathered}
$$

For a two-DOF milling system considering the single dominant structural mode in two orthogonal directions ( $X$ and $Y$ ), the matrices $\mathbf{A}_{0}$ and $\mathbf{B}(t)$ can be given as

$$
\begin{gathered}
\mathbf{A}_{0}=\left[\begin{array}{cccc}
0 & 0 & 1 & 0 \\
0 & 0 & 0 & 1 \\
-\omega_{n x}^{2} & 0 & -2 \zeta_{x} \omega_{n x} & 0 \\
0 & -\omega_{n y}^{2} & 0 & -2 \zeta_{y} \omega_{n y}
\end{array}\right] \\
\mathbf{B}(t)=\left[\begin{array}{cccc}
0 & 0 & 0 & 0 \\
0 & 0 & 0 & 0 \\
\frac{a_{p} h_{x x}(t)}{m_{x}} & \frac{a_{p} h_{x y}(t)}{m_{x}} & 0 & 0 \\
\frac{a_{p} h_{y x}(t)}{m_{y}} & \frac{a_{p} h_{y y}(t)}{m_{y}} & 0 & 0
\end{array}\right]
\end{gathered}
$$

where $m_{x}, \zeta_{x}$, and $\omega_{n x}$ are the modal mass, damping ratio, and angular natural frequency in the $X$ direction, respectively, and $m_{y}, \zeta_{y}$, and $\omega_{n y}$ are the modal mass, damping ratio, and angular natural frequency in the $Y$ direction, respectively. The directional cutting force coefficients $h_{x x}(t), h_{x y}(t), h_{y x}(t)$, and $h_{y y}(t)$ are given as follows:

$$
\begin{aligned}
& h_{x x}(t)=\sum_{j=1}^{N} g\left[\varphi_{j}(t)\right] \sin \left(\left(\varphi_{j}(t)\right)\left[K_{t c} \cos \left(\varphi_{j}(t)\right)+K_{r c} \sin \left(\varphi_{j}(t)\right)\right]\right. \\
& h_{x y}(t)=\sum_{j=1}^{N} g\left[\varphi_{j}(t)\right] \cos \left(\left(\varphi_{j}(t)\right)\left[K_{t c} \cos \left(\varphi_{j}(t)\right)+K_{r c} \sin \left(\varphi_{j}(t)\right)\right]\right. \\
& h_{y x}(t)=\sum_{j=1}^{N} g\left[\varphi_{j}(t)\right] \sin \left(\left(\varphi_{j}(t)\right)\left[-K_{t c} \sin \left(\varphi_{j}(t)\right)+K_{r c} \cos \left(\varphi_{j}(t)\right)\right]\right. \\
& h_{y y}(t)=\sum_{j=1}^{N} g\left[\varphi_{j}(t)\right] \cos \left(\left(\varphi_{j}(t)\right)\left[-K_{t c} \sin \left(\varphi_{j}(t)\right)+K_{r c} \cos \left(\varphi_{j}(t)\right)\right]\right.
\end{aligned}
$$

where $K_{t c}$ and $K_{r c}$ are the tangential and the normal cutting force coefficients, respectively. $g\left[\varphi_{j}(t)\right]$ is a window function which determines whether the tooth is in or out of the cut, where $\varphi_{j}(t)$ is the angular position of the tooth $j$, and it is given as follows:

$$
\varphi_{j}(t)=(2 \pi \Omega / 60) t+(j-1) 2 \pi / N
$$




\section{The proposed method}

In this study, the tooth passing period is divided into two subintervals, i.e., the free and forced vibration intervals. After that, the forced vibration interval $T_{f_{o}}$ is divided into $n$ equal small-time intervals with the step length of $h$. Then, the time point $t_{i}$ can be represented as follows:

$$
t_{i}=t_{0}+T_{f_{r}}+(i-1) h, i=1,2, \ldots, n+1
$$

where $t_{0}$ is the initial time point, and $T_{f r}$ is the free vibration interval. Science the milling system experiences free vibration from the time point $t_{n+1-T}$ to the time point $t_{1}$, the $\mathbf{U}\left(t_{1}\right)$ and $\mathbf{U}\left(t_{n+1-T}\right)$ denoted as $\mathbf{U}_{1}$ and $\mathbf{U}_{n+1-T}$ have the following relation

$$
\mathbf{U}_{1}=e^{\mathbf{A}_{0} T_{f r}} \mathbf{U}_{n+1-T}
$$

Equation (2) is solved on the interval $\left[t_{i-1}, t_{i+1}\right]$, we can get

$$
\mathbf{U}_{i+1}=e^{2 \mathbf{A}_{i} h} \mathbf{U}_{i}+\int_{t_{i-1}}^{t_{i+1}} e^{\mathbf{A}_{i}\left(t_{i+1}-s\right)} \mathbf{B}(s) \mathbf{U}(s-T) d s
$$

where $\mathbf{U}_{i+1}$ and $\mathbf{U}_{i}$ are the abbreviations of the $\mathbf{U}\left(t_{i+1}\right)$ and $\mathbf{U}\left(t_{i}\right)$, respectively.

Define $\rho(s)=e^{\mathbf{A}_{i}\left(t_{i+1}-s\right)} \mathbf{B}(s) \mathbf{U}(s-T)$, Eq. (17) can be rewritten as follows:

$$
\mathbf{U}_{i+1}=e^{2 \mathbf{A}_{i} h} \mathbf{U}_{i}+\int_{t_{i-1}}^{t_{i+1}} \rho(s) d s
$$

Then, based on two-step Simpson method, the following result can be obtained

$$
\int_{t_{i-1}}^{t_{i+1}} \rho(s) d s=\frac{h}{3}\left(e^{2 \mathbf{A}_{i} h} \mathbf{B}_{i-1} \mathbf{U}_{i-1-T}+4 e^{\mathbf{A}_{i} h} \mathbf{B}_{i} \mathbf{U}_{i-T}+\mathbf{B}_{i+1} \mathbf{U}_{i+1-T}\right)
$$

where $\mathbf{U}_{i-1-T}, \mathbf{U}_{i-T}$, and $\mathbf{U}_{i+1-T}$ are the abbreviations of the $\mathbf{U}\left(t_{i-1}-T\right), \mathbf{U}\left(t_{i}-T\right)$ and $\mathbf{U}\left(t_{i+1}-T\right)$, respectively.

Equation (19) is inserted into Eq. (18), we can get

$$
-\mathbf{F}_{i}^{2} \mathbf{U}_{i}+\mathbf{U}_{i+1}=\mathbf{E}_{i-1} \mathbf{U}_{i-1-T}+\mathbf{E}_{i} \mathbf{U}_{i-T}+\mathbf{E}_{i+1} \mathbf{U}_{i+1-T}
$$

where

$$
\begin{aligned}
\mathbf{F}_{i} & =e^{\mathbf{A}_{i} h} \\
\mathbf{E}_{i-1} & =\frac{h}{3} e^{2 \mathbf{A}_{i} h} \mathbf{B}_{i-1} \\
\mathbf{E}_{i} & =\frac{4 h}{3} e^{\mathbf{A}_{i} h} \mathbf{B}_{i} \\
\mathbf{E}_{i+1} & =\frac{h}{3} \mathbf{B}_{i+1}
\end{aligned}
$$

When $i=1$, the trapezoidal rule is used to solve the Eq. (2) on the interval $\left[t_{i}, t_{i+1}\right]$, we can get

$$
-\mathbf{F}_{i} \mathbf{U}_{i}+\mathbf{U}_{i+1}=\mathbf{G}_{i} \mathbf{U}_{i-T}+\mathbf{G}_{i+1} \mathbf{U}_{i+1-T}
$$

where

$$
\mathbf{G}_{i}=\frac{h}{2} e^{\mathbf{A}_{i} h} \mathbf{B}_{i}
$$




$$
\mathbf{G}_{i+1}=\frac{h}{2} \mathbf{B}_{i+1}
$$

According to Eqs. (16), (20), and (25), the following mapping relation can be obtained as

$$
\mathbf{D}_{1}\left[\begin{array}{c}
\mathbf{U}_{1} \\
\mathbf{U}_{2} \\
\mathbf{M} \\
\mathbf{U}_{n-1} \\
\mathbf{U}_{n} \\
\mathbf{U}_{n+1}
\end{array}\right]=\mathbf{D}_{2}\left[\begin{array}{c}
\mathbf{U}_{1-T} \\
\mathbf{U}_{2-T} \\
\mathbf{M} \\
\mathbf{U}_{n-1-T} \\
\mathbf{U}_{n-T} \\
\mathbf{U}_{n+1-T}
\end{array}\right]
$$

where

$$
\begin{aligned}
& \mathbf{D}_{1}=\left[\begin{array}{cccccccccc}
\mathbf{I} & \mathbf{0} & \mathbf{0} & \mathbf{0} & \mathbf{0} & \mathrm{L} & \mathbf{0} & \mathbf{0} & \mathbf{0} & \mathbf{0} \\
\mathbf{0} & -\mathbf{F}_{1} & \mathbf{I} & \mathbf{0} & \mathbf{0} & \mathrm{L} & \mathbf{0} & \mathbf{0} & \mathbf{0} & \mathbf{0} \\
-\mathbf{F}_{2}^{2} & \mathbf{0} & \mathbf{I} & \mathbf{0} & \mathbf{0} & \mathrm{L} & \mathbf{0} & \mathbf{0} & \mathbf{0} & \mathbf{0} \\
\mathbf{0} & -\mathbf{F}_{3}^{2} & \mathbf{0} & \mathbf{I} & \mathbf{0} & \mathrm{L} & \mathbf{0} & \mathbf{0} & \mathbf{0} & \mathbf{0} \\
\mathbf{0} & \mathbf{0} & -\mathbf{F}_{4}^{2} & \mathbf{0} & \mathbf{I} & \mathrm{L} & \mathbf{0} & \mathbf{0} & \mathbf{0} & \mathbf{0} \\
\mathrm{M} & \mathrm{M} & \mathrm{M} & \mathrm{M} & \mathrm{M} & \mathrm{O} & \mathrm{M} & \mathrm{M} & \mathrm{M} & \mathrm{M} \\
\mathbf{0} & \mathbf{0} & \mathbf{0} & \mathbf{0} & \mathbf{0} & \mathrm{L} & -\mathbf{F}_{n-1}^{2} & \mathbf{0} & \mathbf{I} & \mathbf{0} \\
\mathbf{0} & \mathbf{0} & \mathbf{0} & \mathbf{0} & \mathbf{0} & \mathrm{L} & \mathbf{0} & -\mathbf{F}_{n}^{2} & \mathbf{0} & \mathbf{I}
\end{array}\right] \\
& \mathbf{D}_{2}=\left[\begin{array}{cccccccccc}
\mathbf{I} & \mathbf{0} & \mathbf{0} & \mathbf{0} & \mathbf{0} & \mathrm{L} & \mathbf{0} & \mathbf{0} & \mathbf{0} & e^{\mathbf{A}_{0} T_{t f}} \\
\mathbf{0} & \mathbf{G}_{1} & \mathbf{G}_{2} & \mathbf{0} & \mathbf{0} & \mathrm{L} & \mathbf{0} & \mathbf{0} & \mathbf{0} & \mathbf{0} \\
\mathbf{E}_{1} & \mathbf{E}_{2} & \mathbf{E}_{3} & \mathbf{0} & \mathbf{0} & \mathrm{L} & \mathbf{0} & \mathbf{0} & \mathbf{0} & \mathbf{0} \\
\mathbf{0} & \mathbf{E}_{2} & \mathbf{E}_{3} & \mathbf{E}_{4} & \mathbf{0} & \mathrm{L} & \mathbf{0} & \mathbf{0} & \mathbf{0} & \mathbf{0} \\
\mathbf{0} & \mathbf{0} & \mathbf{E}_{4} & \mathbf{E}_{5} & \mathbf{E}_{6} & \mathrm{~L} & \mathbf{0} & \mathbf{0} & \mathbf{0} & \mathbf{0} \\
\mathrm{M} & \mathrm{M} & \mathrm{M} & \mathrm{M} & \mathrm{M} & \mathrm{O} & \mathrm{M} & \mathrm{M} & \mathrm{M} & \mathrm{M} \\
\mathbf{0} & \mathbf{0} & \mathbf{0} & \mathbf{0} & \mathbf{0} & \mathrm{L} & \mathbf{E}_{n-2} & \mathbf{E}_{n-1} & \mathbf{E}_{n} & \mathbf{0} \\
\mathbf{0} & \mathbf{0} & \mathbf{0} & \mathbf{0} & \mathbf{0} & \mathrm{L} & \mathbf{0} & \mathbf{E}_{n-1} & \mathbf{E}_{n} & \mathbf{E}_{n+1}
\end{array}\right]
\end{aligned}
$$

The state transition matrix $\boldsymbol{\Psi}$ of the milling system can be obtained as

$$
\boldsymbol{\Psi}=\left(\mathbf{D}_{1}\right)^{-1} \mathbf{D}_{2}
$$

Based on Floquet theory, the milling stability can be predicted according to the spectral radius of the state transition matrix [10].

To improve the computational efficiency of the proposed method, the precise integration algorithm [44] is used for calculating the matrix exponent $e^{\mathbf{A}_{i} h}$, and the precision exponent is chosen as 2, which is the same as that adopted in Ref. [29]. 


\section{Comparison and discussion}

\subsection{Convergence rate}

The convergence rate can be taken as the criterion to evaluate the accuracy of the stability prediction methods. Normally, the method with higher convergence rate is relatively more accurate. In Refs. [13-43], the local discretization error calculated by $|\mu(n)|-\left|\mu_{0}\right| \mid$ is employed for the analysis of convergence rate, where $|\mu(n)|$ and $\left|\mu_{0}\right|$ are the approximated and exact spectral radius of the state transition matrix. The convergence rate reflects how fast the local discretization error approaches zero. When the discrete number $n$ is large enough, the local discretization error calculated by the prediction methods will approach zero. In this work, $\left|\mu_{0}\right|$ is determined using 1 st SDM with $n=600$. To evaluate the convergence rate of the proposed method, the 1st SDM, 2nd SDM, SBM, and PCSDM are taken as the benchmark. The spindle speed $\Omega$ is set as $5000 \mathrm{rpm}$, and the axial depth of cuts $a_{p}$ is set as $0.2,0.5,1.0 \mathrm{~mm}$. A milling cutter with two flutes is used in the calculation. The main parameters are chosen as the same as those used in Ref. [10]. The machining parameters are: the radial immersion ratio is $a / D=1$, down milling. The tangential and the normal cutting force coefficients are $K_{t c}=600 \mathrm{MPa}$ and $K_{r c}=200 \mathrm{MPa}$, respectively. The modal parameters are: $\omega_{n x}=5793.1 \mathrm{rad} / \mathrm{s}, m_{x}=0.03993 \mathrm{~kg}$, and $\zeta_{x}=0.011$. The comparison among the convergence rates of the 1st SDM, 2nd SDM, SBM, PCSDM, and proposed USBM are shown in Fig. 1.

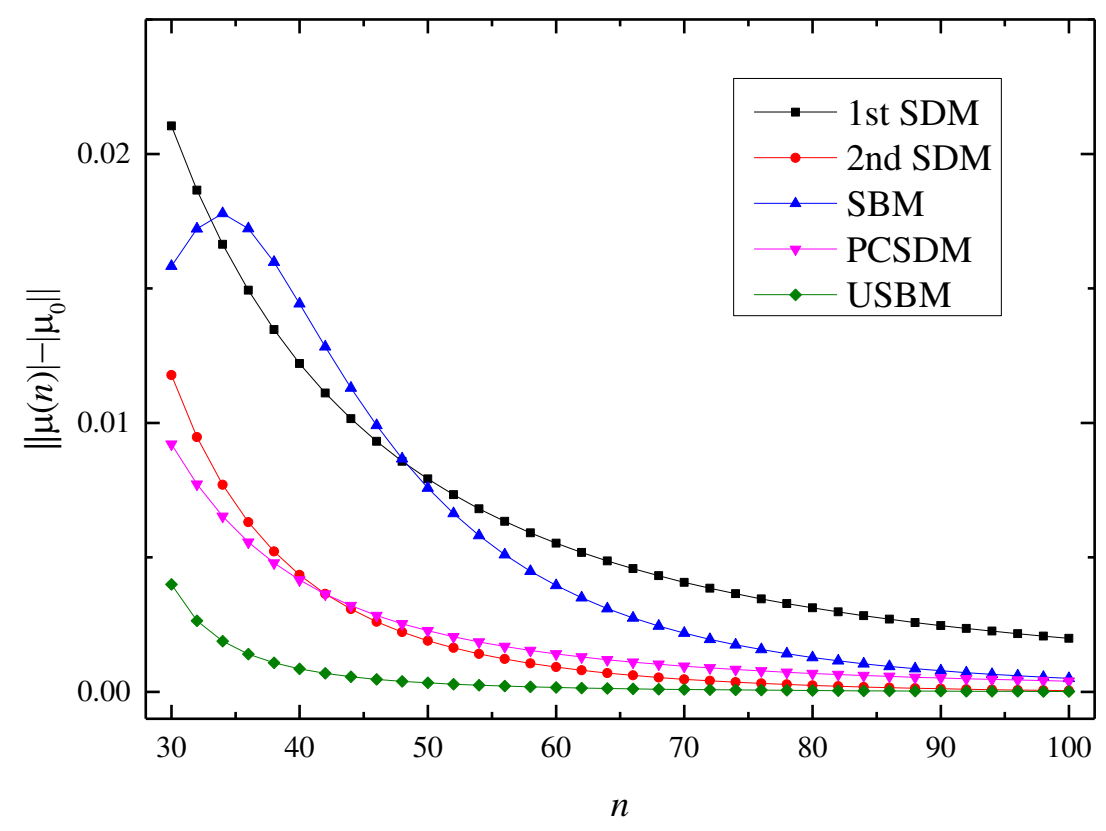

(a) $a_{p}=0.2 \mathrm{~mm},\left|\mu_{0}\right|=0.81971$ (stable) 


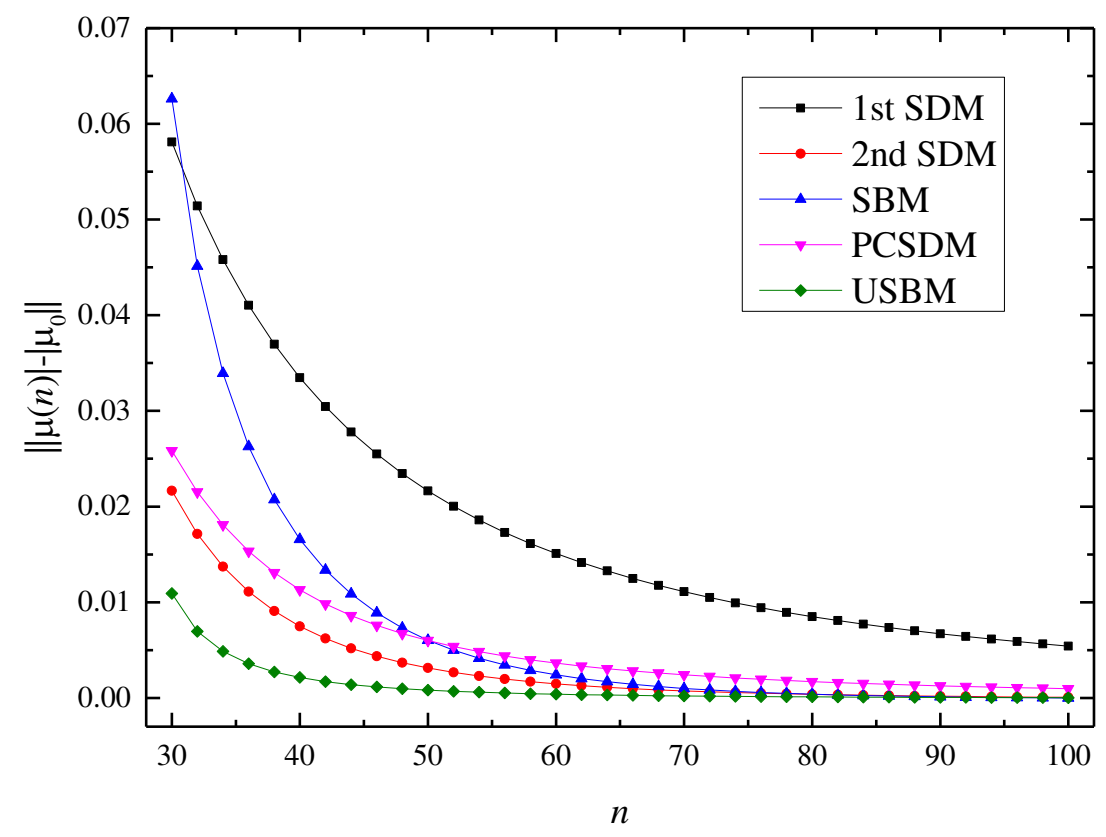

(b) $a_{p}=0.5 \mathrm{~mm},\left|\mu_{0}\right|=1.07389$ (unstable)

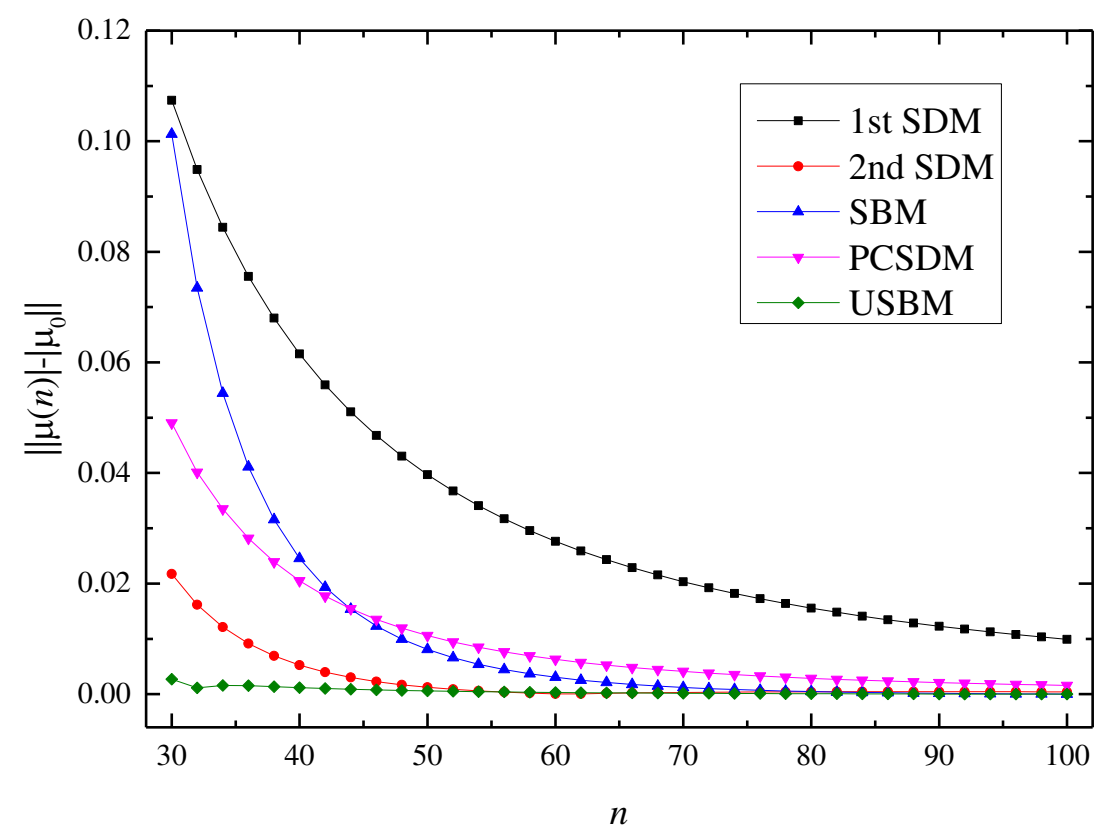

(c) $a_{p}=1.0 \mathrm{~mm},\left|\mu_{0}\right|=1.40632$ (unstable)

Fig. 1 Comparison among the convergence rates of the 1st SDM, 2nd SDM, SBM, PCSDM and proposed method (USBM).

Fig. 1 exhibits that no matter what axial depth of cut $a_{p}$ is, the proposed USBM converges faster than the benchmark methods. As shown in Fig. 1(a) and (b), when $a_{p}=0.2$ and $0.5 \mathrm{~mm}$, the local discretization error calculated by the USBM approaches zero when $n$ equals 40 , while that calculated by the benchmark methods tends to be zero when $n$ is much larger than 40. In Fig. 1(c), when $a_{p}=1$ and $n=30$, the local discretization error obtained by the USBM almost equals zero, while that obtained by the benchmark methods is larger than 0.02 . 


\subsection{Stability lobe diagram}

\subsubsection{One-DOF milling}

In section 4.1, the accuracy of the proposed method is verified from the aspect of convergence rate. In this section, the accuracy and efficiency of the proposed method are further validated from the aspect of the stability lobe diagram (SLD). The proposed method is compared with the 1st SDM, SBM, 2nd SDM, and PCSDM in terms of the SLD. Firstly, the one-DOF milling system is used for validation. The SLDs are generated on a parameter plane with the spindle speed $\Omega \in[5000,10000]$ $\mathrm{rpm}$ and the axial depth of cut $a_{p} \in[0,0.004] \mathrm{m}$. The parameter plane is divided into a $200 \times 200$ sized equidistance grid. The reference is the SLD determined by the SBM with $n=300$ and presented by red curves. The radical immersion ratio $a / D$ is chosen as 1.0. The SLDs calculated by the 1st SDM, SBM, 2nd SDM, PCSDM, and proposed USBM with $n=30$ and 40 for the one-DOF milling system are presented in Fig. 2.

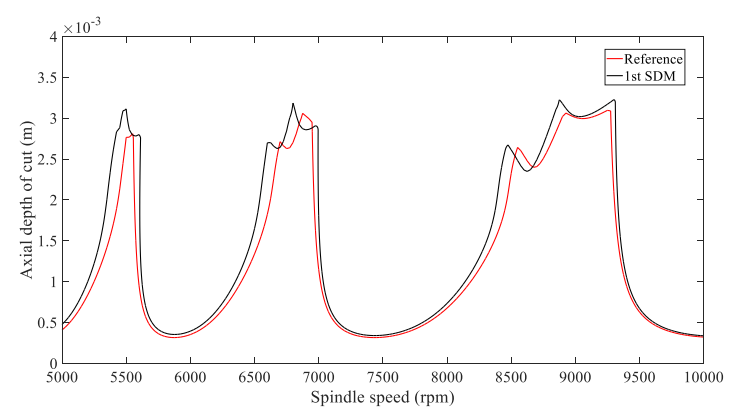

(a) $1 \mathrm{st} \mathrm{SDM}, n=30$, time $=284 \mathrm{~s}$

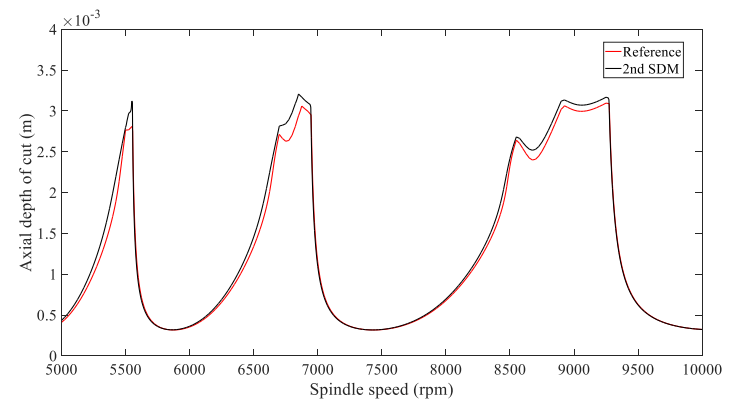

(c) 2nd SDM, $n=30$, time $=42 \mathrm{~s}$

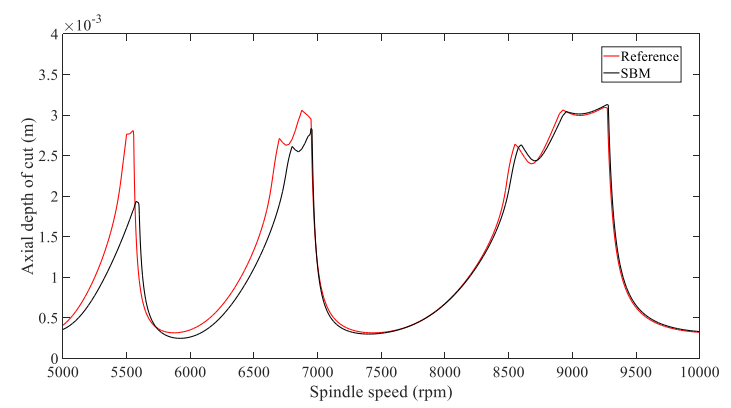

(e) SBM, $n=30$, time $=22 \mathrm{~s}$

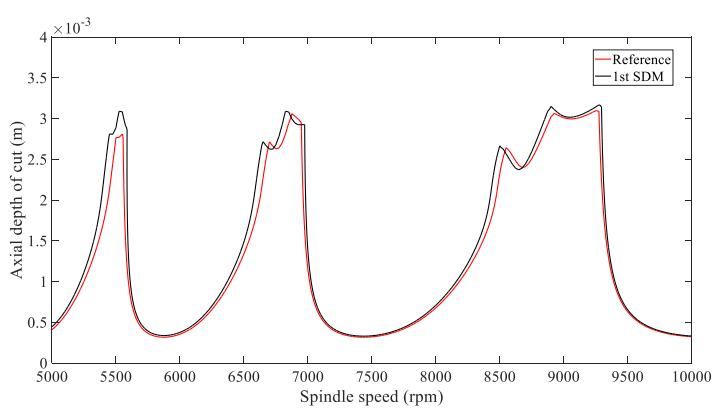

(b) $1 \mathrm{st}$ SDM, $n=40$, time $=408 \mathrm{~s}$

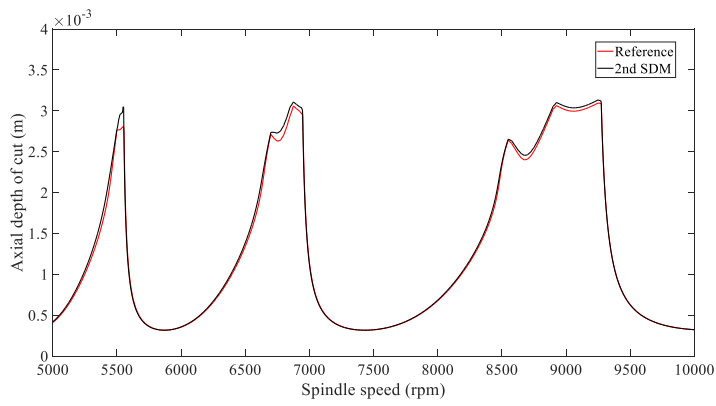

(d) 2nd SDM, $n=40$, time $=64 \mathrm{~s}$

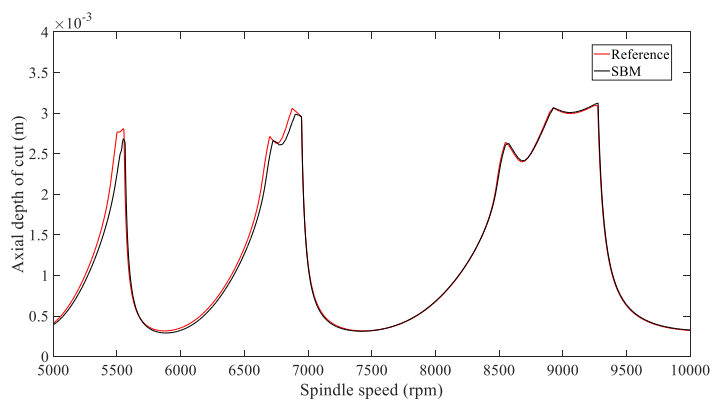

(f) SBM, $n=40$, time $=39 \mathrm{~s}$ 


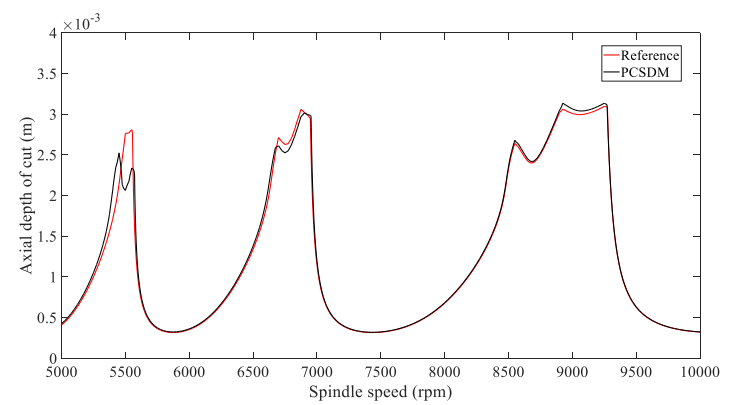

(g) PCSDM, $n=30$, time $=127 \mathrm{~s}$

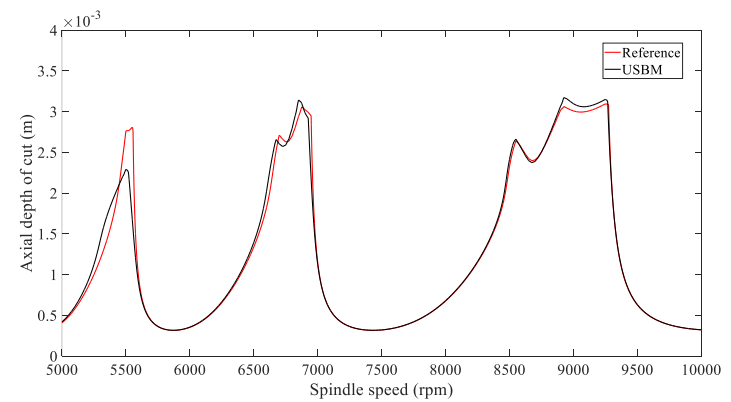

(i) USBM, $n=30$, time $=25 \mathrm{~s}$

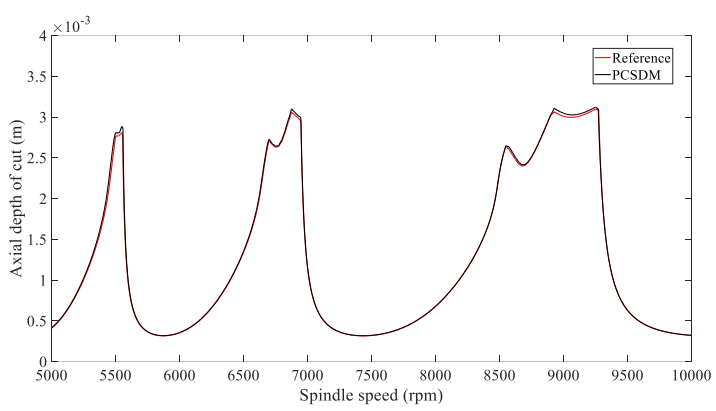

(h) PCSDM, $n=40$, time $=178 \mathrm{~s}$

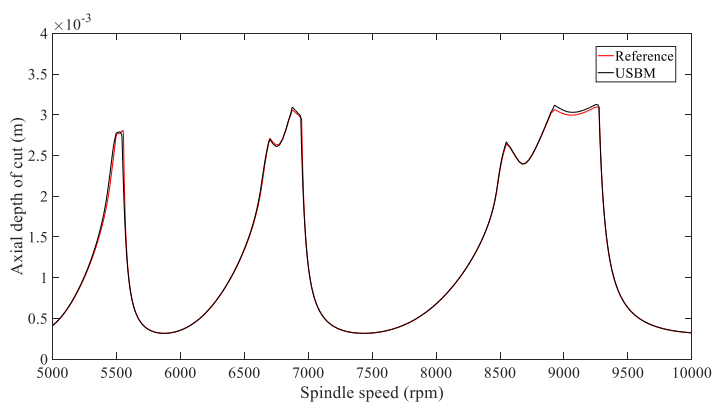

(j) USBM, $n=40$, time $=43 \mathrm{~s}$

Fig. 2 The SLDs calculated by the 1st SDM, SBM, 2nd SDM, PCSDM, and USBM with $n=30$ and 40 for the one-DOF milling system $(a / D=1.0)$.

As shown in Fig. 2, when $n$ takes the same value (30 and 40), the SLDs obtained by the USBM and PCSDM are closer to the reference than those obtained by the 1st SDM, SBM, and 2nd SDM. Regarding the computational time, the SBM and USBM consume less time than the 1st SDM, 2nd SDM, and PCSDM to generate SLDs. Although the USBM takes slightly more time than the SBM, the result predicted by the USBM is more accurate than that predicted by the SBM. The time increment between the USBM and SBM is small. Through contrastive analysis, it is revealed that the proposed USBM has advantages in both prediction accuracy and computational efficiency.

The stability of the one-DOF milling system under the low immersion condition $(a / D=0.05)$ is also predicted. The SLD is also plotted on a $200 \times 200$ sized equidistance grid with $\Omega \in[5000,10000] \mathrm{rpm}$ and $a_{p} \in[0,0.01] \mathrm{m}$. The comparison of the SLDs calculated by the 1st SDM, SBM, 2nd SDM, PCSDM, and USBM with $n=20$ and 30 for the one-DOF milling system is presented in Fig. 3.

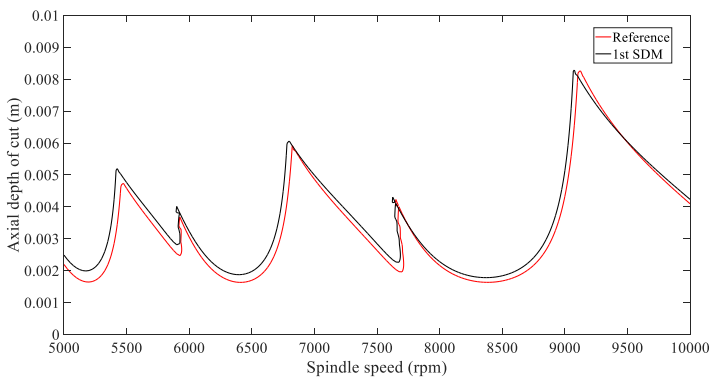

(a) 1 st SDM, $n=20$, time $=192 \mathrm{~s}$

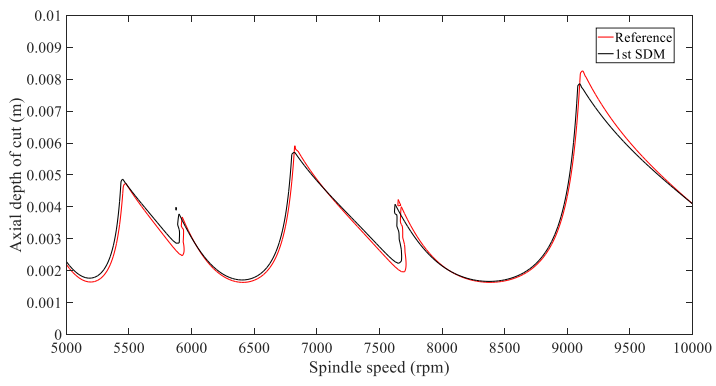

(b) 1 st SDM, $n=30$, time $=278 \mathrm{~s}$ 


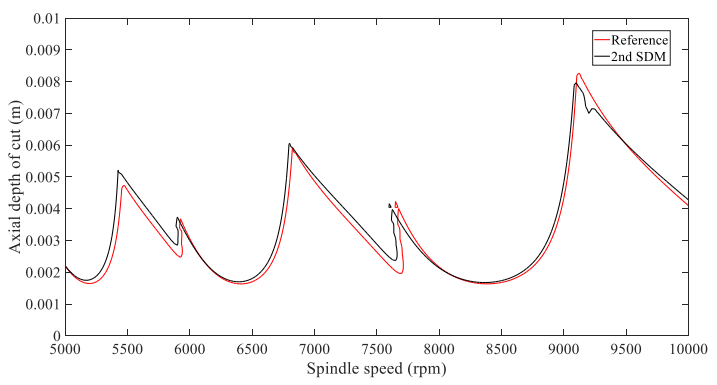

(c) 2nd SDM, $n=20$, time $=24 \mathrm{~s}$

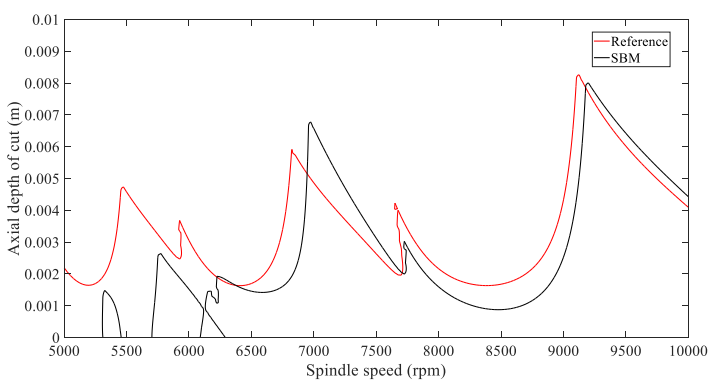

(e) SBM, $n=20$, time $=10 \mathrm{~s}$

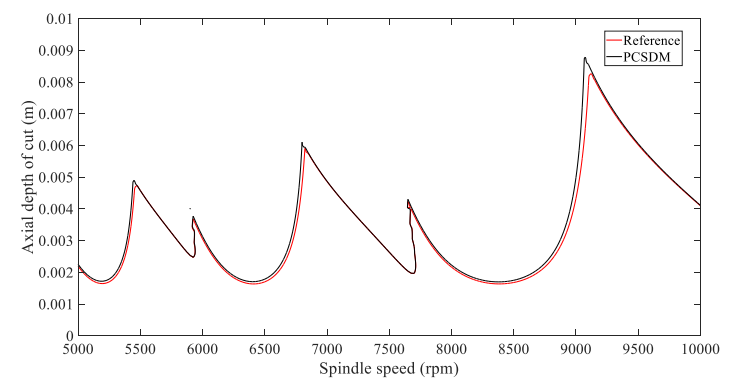

(g) PCSDM, $n=20$, time $=72 \mathrm{~s}$

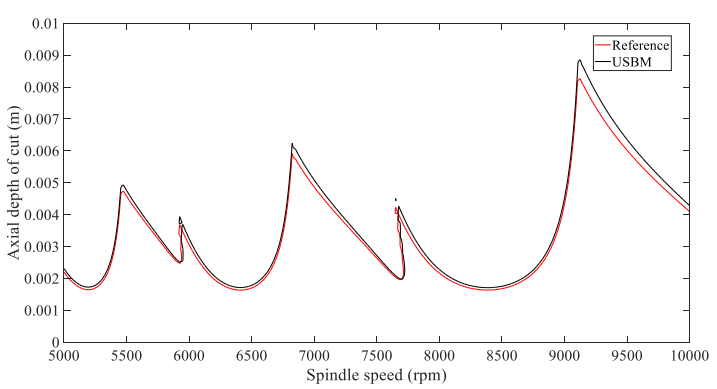

(i) USBM, $n=20$, time $=13 \mathrm{~s}$

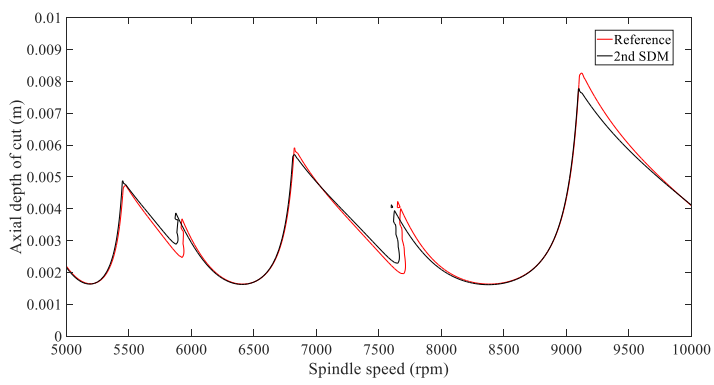

(d) 2nd SDM, $n=30$, time $=36 \mathrm{~s}$

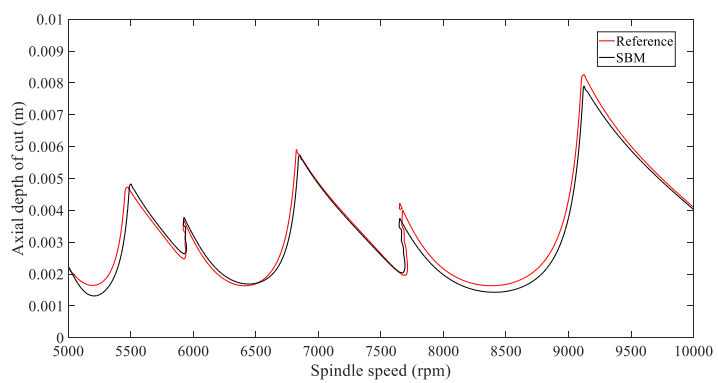

(f) SBM, $n=30$, time $=17 \mathrm{~s}$

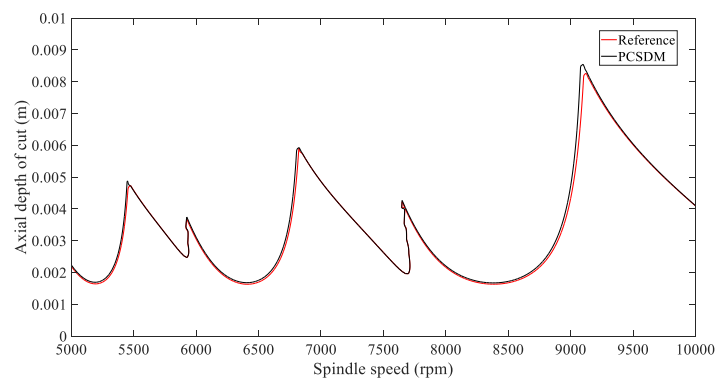

(h) PCSDM, $n=30$, time $=115 \mathrm{~s}$

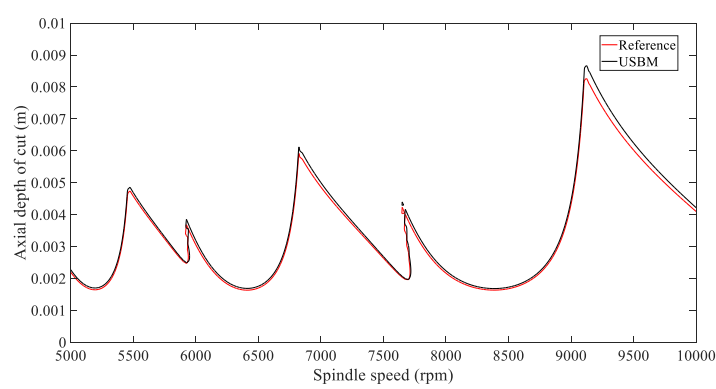

(j) USBM, $n=30$, time $=24 \mathrm{~s}$

Fig. 3 Comparison of the SLD calculated by the 1st SDM, SBM, 2nd SDM, PCSDM, and USBM with $n=20$ and 30 for the one-DOF milling system.

As shown in Fig. 3, PCSDM has advantages in prediction accuracy but not in computation efficiency. The existing SBM is an efficient method, but whose prediction accuracy needs to be improved. Unlike the benchmark methods, the proposed USBM can achieve both high accuracy and high efficiency. 


\subsubsection{Two-DOF milling}

To further evaluate the effectiveness of the USBM, the two-DOF milling system is also considered in this study. The cutting force coefficients are the same as those used in section 4.1. The modal parameters in the $X$ and $Y$ directions are assumed to be equal and listed as follows: $\omega_{n x}=\omega_{n y}=5793 \mathrm{rad} / \mathrm{s}, \zeta_{x}=\zeta_{y}=0.011$, and $m_{x}=m_{y}=0.03993 \mathrm{~kg}$. The SLD is plotted on a $200 \times 200$ sized equidistance grid with $\Omega \in[5000,25000] \mathrm{rpm}$ and $a_{p} \in[0,0.001] \mathrm{m}$. The SLD determined by the SBM with $n=300$ is regarded as the reference. The SLDs obtained by different methods with $n=20$ and 30 for the two-DOF milling system under the large immersion condition $(a / D=1.0)$ are presented in Fig. 4.

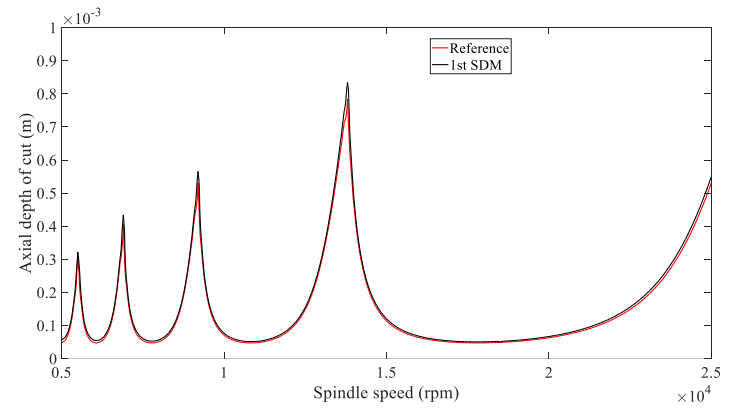

(a) $1 \mathrm{st} \mathrm{SDM}, n=20$, time $=247 \mathrm{~s}$

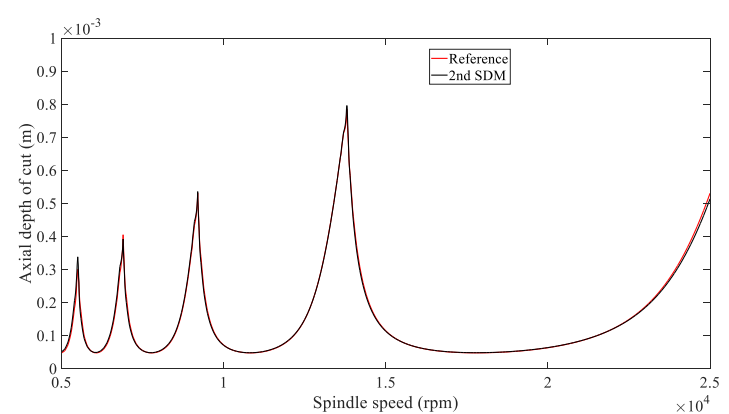

(c) 2nd SDM, $n=20$, time $=112 \mathrm{~s}$

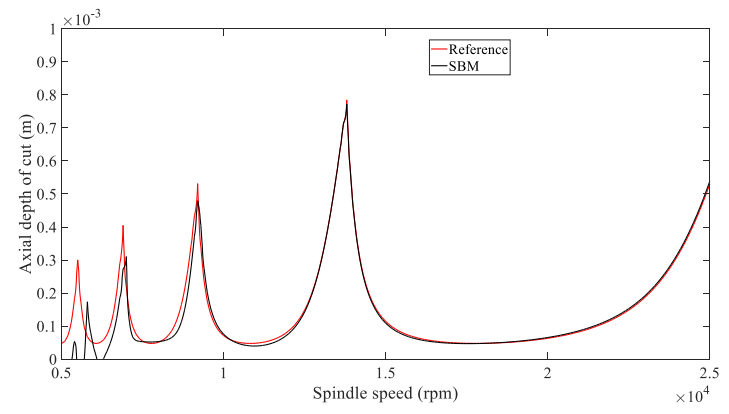

(e) SBM, $n=20$, time $=30 \mathrm{~s}$

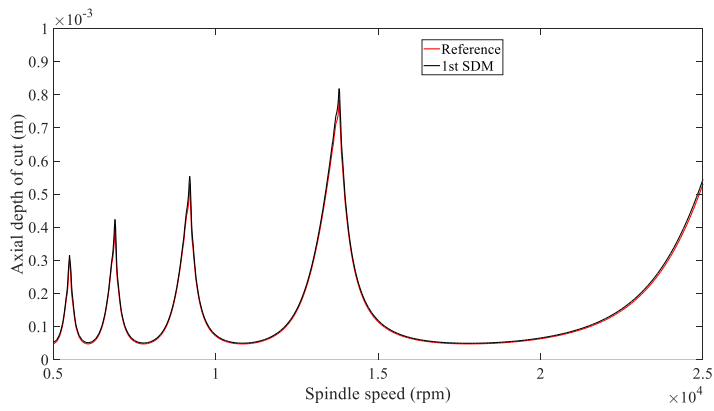

(b) $1 \mathrm{st} \mathrm{SDM}, n=30$, time $=366 \mathrm{~s}$

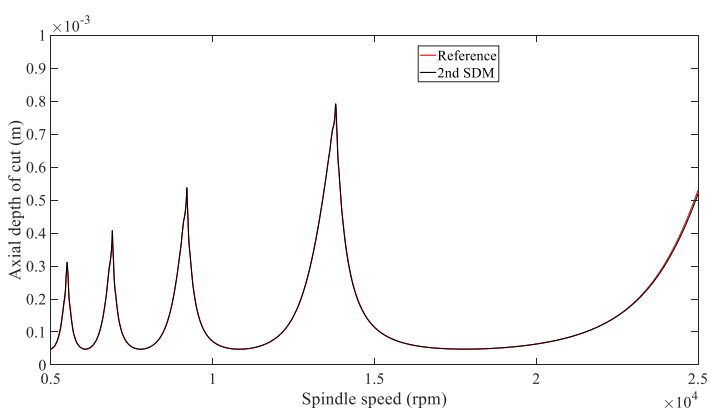

(d) 2nd SDM, $n=30$, time $=157 \mathrm{~s}$

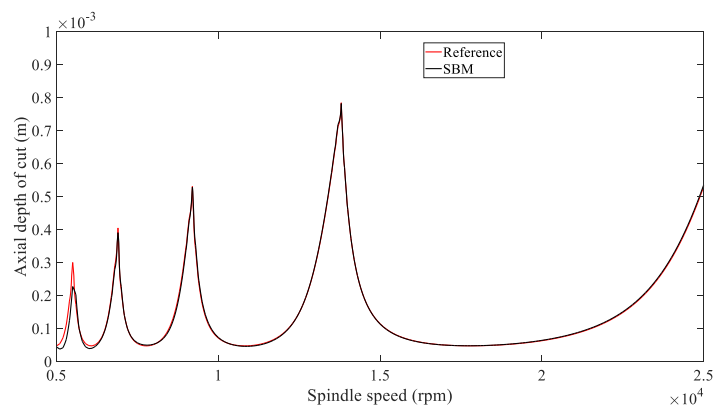

(f) SBM, $n=30$, time $=53 \mathrm{~s}$ 


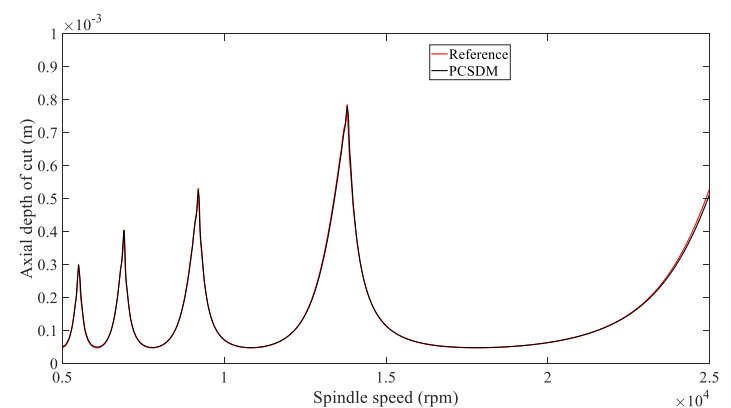

(g) PCSDM, $n=20$, time $=99 \mathrm{~s}$

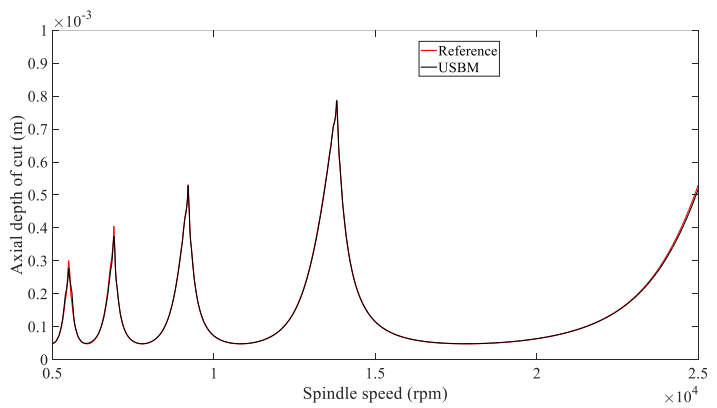

(i) USBM, $n=20$, time $=31 \mathrm{~s}$

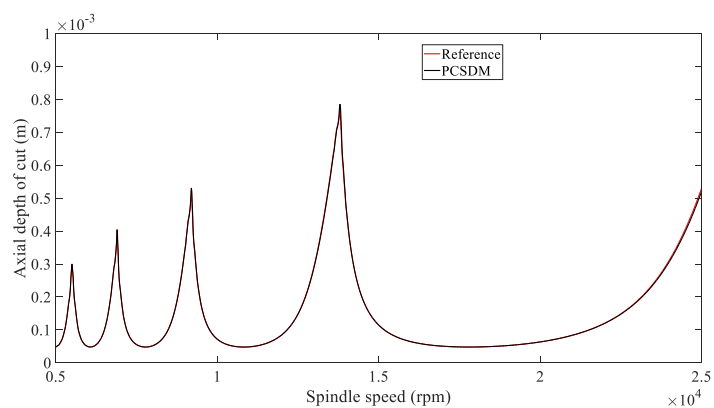

(h) PCSDM, $n=30$, time $=155 \mathrm{~s}$

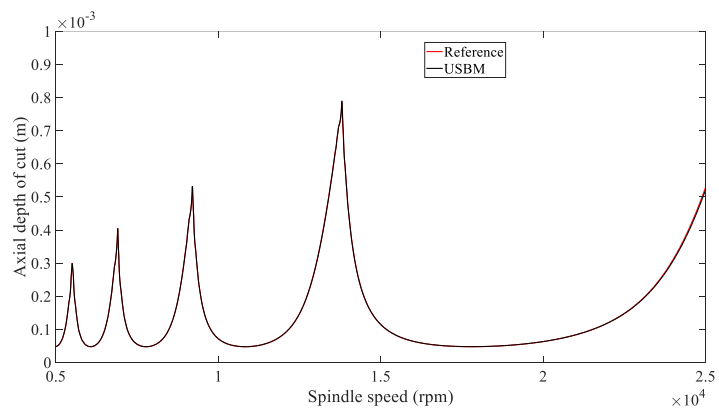

(j) USBM, $n=30$, time $=55 \mathrm{~s}$

Fig. 4 The SLDs obtained by different methods with $n=20$ and 30 for the two-DOF milling system under large immersion condition $(a / D=1.0)$.

As shown in Fig. 4, the SBM takes the least time to generate SLDs; however, the SLDs obtained by the 1st SDM, 2nd SDM, PCSDM, and USBM are closer to the reference than those obtained by the SBM. In Fig. 4, when $n=20$ and 30, the increment of computational time between the SBM and USBM is one second and two seconds, respectively, which indicates that the efficiency of the SBM and USBM is almost the same. The comparison shows that the USBM can predict the milling stability for the two-DOF milling system under the large immersion condition accurately and efficiently.

The SLDs obtained by the 1st SDM, SBM, 2nd SDM, PCSDM, and USBM with $n=20$ and 30 for the 2 -DOF milling system under low immersion condition $(\mathrm{a} / \mathrm{D}=0.05)$ are presented in Fig. 5.

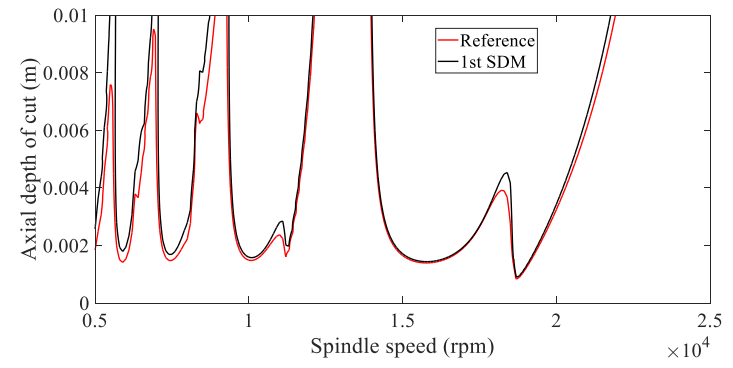

(a) $1 \mathrm{st} \mathrm{SDM}, n=20$, time $=235 \mathrm{~s}$

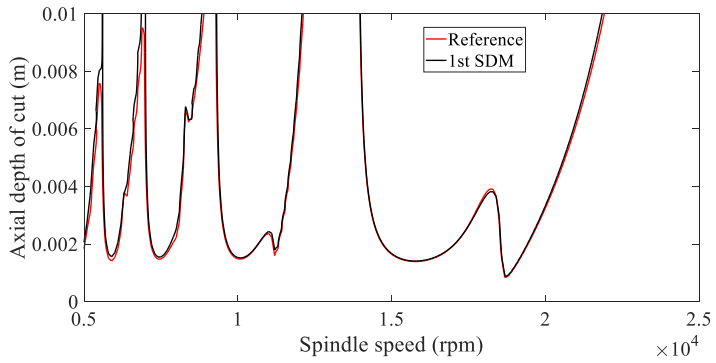

(b) $1 \mathrm{st}$ SDM, $n=30$, time $=352 \mathrm{~s}$ 


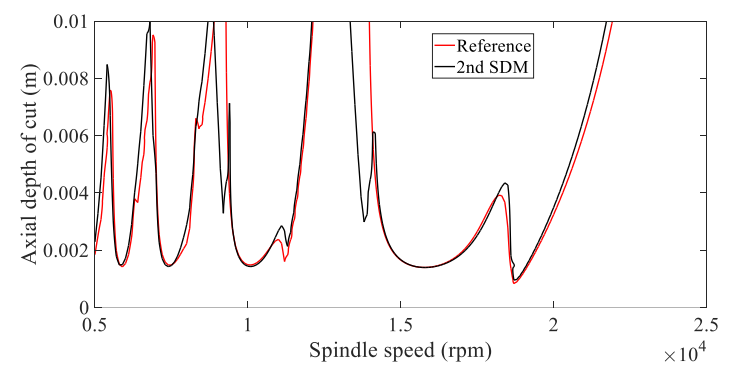

(c) 2nd SDM, $n=20$, time $=89 \mathrm{~s}$

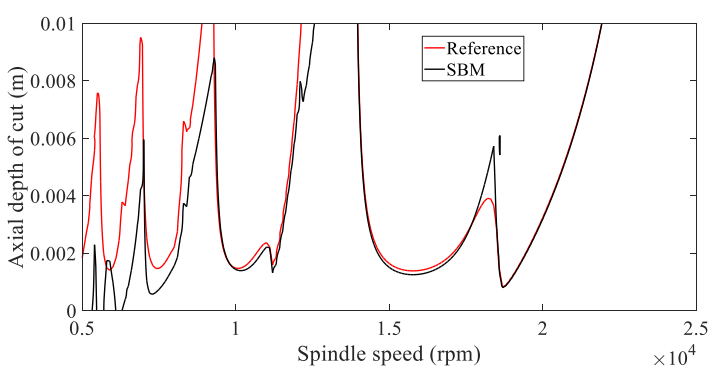

(e) SBM, $n=20$, time $=20 \mathrm{~s}$

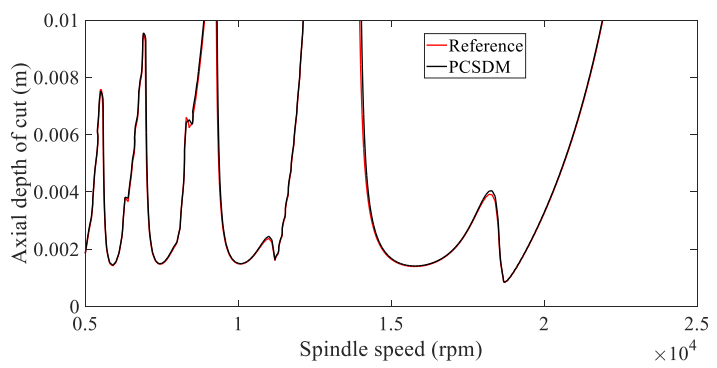

(g) PCSDM, $n=20$, time $=98 \mathrm{~s}$

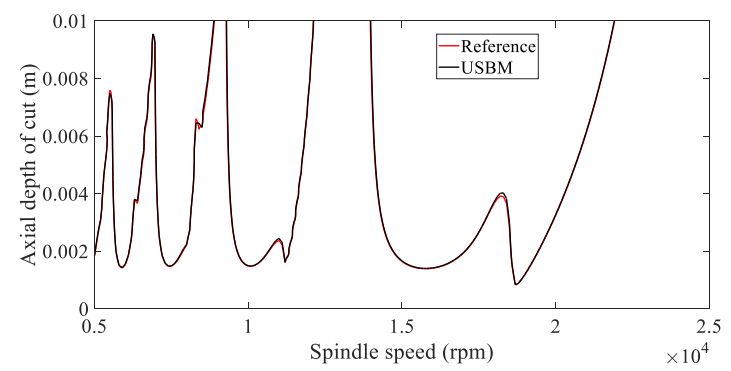

(i) USBM, $n=20$, time $=15 \mathrm{~s}$

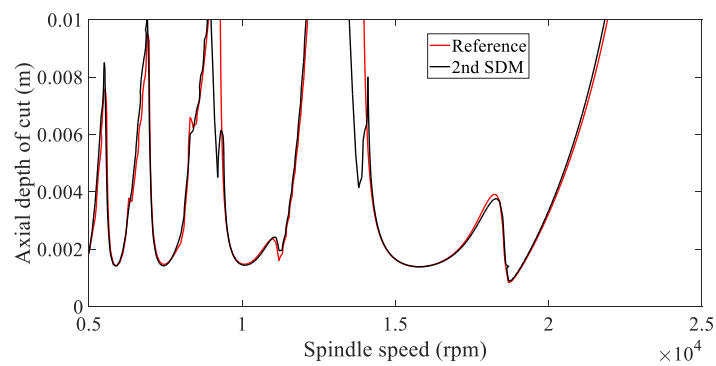

(d) 2nd SDM, $n=30$, time $=139 \mathrm{~s}$

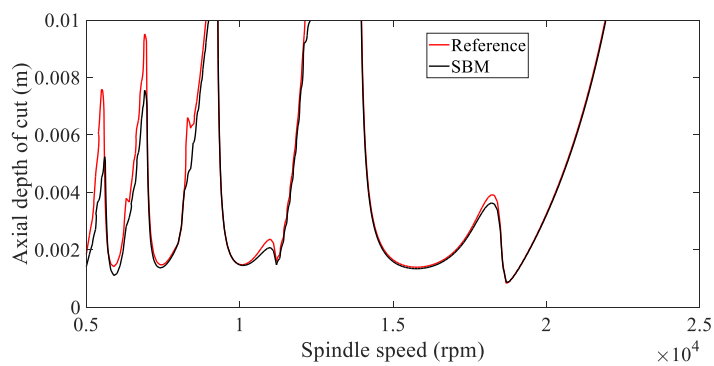

(f) $\mathrm{SBM}, n=30$, time $=31 \mathrm{~s}$

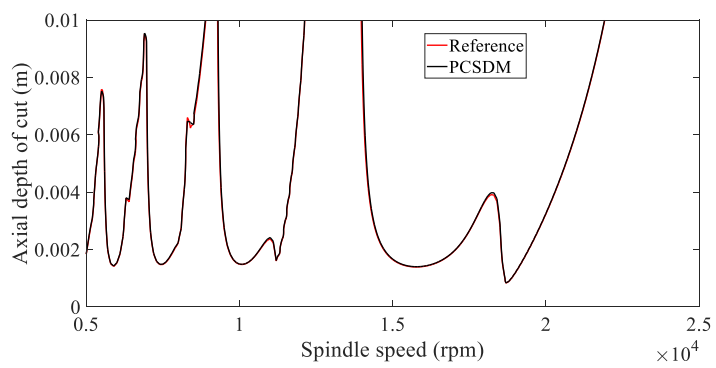

(h) PCSDM, $n=30$, time $=151 \mathrm{~s}$

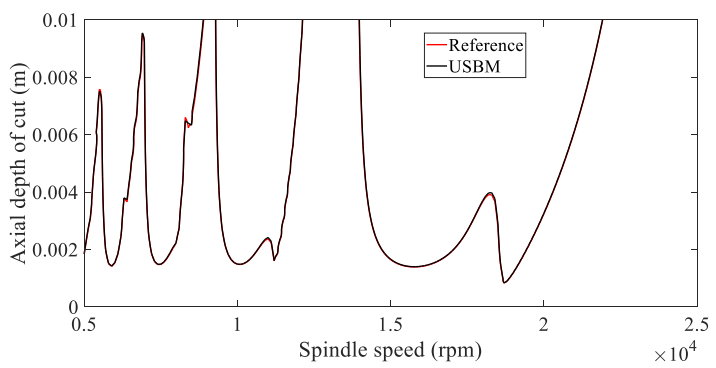

(j) USBM, $n=30$, time $=25 \mathrm{~s}$

Fig. 5 The SLDs obtained by different methods with $n=20$ and 30 for the 2-DOF milling system under low immersion condition $(\mathrm{a} / \mathrm{D}=0.05)$.

As shown in Fig. 5, the prediction accuracy of the PCSDM and the proposed USBM is higher than that of the 1st SDM, 2nd SDM, and SBM. Besides, the efficiency of the proposed USBM is higher than the other methods.

In general, the proposed USBM has good accuracy and efficiency for both one-DOF and two-DOF milling systems and large and low radical immersion conditions.

\section{Conclusions}


This study proposed an updated Simpson-based method for stability prediction in milling. In this study, the two-step Simpson method is employed to solve the DDE in the framework of SDM. The main conclusions sum up as follows:

(1) The proposed USBM converges faster than the benchmark methods. When the discrete number $n$ is identical, the local discretization error obtained by the USBM is less than that obtained by the benchmark methods.

(2) For the one-DOF milling system under the large immersion condition $(a / D=1.0)$, the SLDs obtained by the USBM and PCSDM are closer to the reference than those obtained by the 1st SDM, SBM, and 2nd SDM. Meanwhile, the SBM and USBM consume less time than the 1st SDM, 2nd SDM, and PCSDM to generate SLDs. Generally, the proposed USBM has advantages in both accuracy and efficiency.

(3) Under the low immersion condition $(a / D=0.05)$, the proposed USBM is superior in prediction accuracy and computation efficiency for the one-DOF milling system.

(4) As for the two-DOF milling system, the prediction accuracy of the PCSDM and the proposed USBM is higher than that of the 1st SDM, 2nd SDM, and SBM. Besides, the efficiency of the proposed USBM is higher than the benchmark methods.

Funding information This work was partially supported by the National Natural Science Foundation of China (Grant No. 51805404 and 52075409), Open Research Fund Program of Shaanxi Key Laboratory of Non-traditional Machining (Grant No. 2017SXTZKFJG08), the China Postdoctoral Science Foundation (Grant No. 2019M653570), the key research and development projects in Shaanxi Province (Grant No. 2021GY-272), and the Youth Innovation Team of Shannxi Universities.

Competing interests The authors declare that there is no conflict of interests regarding the publication of this article.

Availability of data and material All data generated or analyzed during this study are included in this published article.

Code availability Not applicable.

Authors' contributions Zhenghu Yan and Changfu Zhang and contributed the central idea, data analysis, and manuscript writing. Jianli Jia, Baoji Ma, and Xinguang Jiang contributed to carrying out additional analyses. Dong Wang, Wei Wang, and Chenxi Yang finalizing this paper. All authors read and approved the final manuscript.

Ethical Approval Not applicable.

Consent to Participate Not applicable.

Consent to Publish Not applicable.

\section{References}

1. Altintas. Y (2000) Manufacturing automation: metal cutting mechanics, machine tool vibrations, and CNC design, Cambridge University Press, Cambridge, UK.

2. Altintas Y, Budak E (1995) Analytical Prediction of Stability Lobes in Milling. CIRP Ann-Manuf Techn 44(1):357-362. https://doi.org/10.1016/S0007-8506(07)62342-7 
3. Merdol SD, Altintas Y (2004) Multi Frequency Solution of Chatter Stability for Low Immersion Milling. J Manuf Sci Eng 126(3):459-466. https://doi.org/10.1115/1.1765139

4. Jin G, Zhang QC, Qi HJ, Yan B (2014) A frequency-domain solution for efficient stability prediction of variable helix cutters milling. P I Mech Eng C-J Mec 228(15): 2702-2710. https://doi.org/10.1177/0954406214522614

5. Budak E (2003) An analytical design method for milling cutters with nonconstant pitch to increase stability, part I: theory. J Manuf Sci E-T ASME 125(1): 29-34. https://doi.org/10.1115/1.1536655

6. Budak E (2003) An analytical design method for milling cutters with nonconstant pitch to increase stability, part 2: application. J Manuf Sci E-T ASME 125(1): 35-38. https://doi.org/10.1115/1.1536656

7. Bayly PV, Halley JE, Mann BP, Davies MA (2003) Stability of Interrupted Cutting by Temporal Finite Element Analysis. J Manuf Sci Eng 125(2): 220-225. https://doi.org/10.1115/1.1556860

8. Butcher EA, Bobrenkov OA, Bueler E, Nindujarla P (2009) Analysis of Milling Stability by the Chebyshev Collocation Method: Algorithm and Optimal Stable Immersion Levels. J. Comput. Nonlinear Dynam. 4(3): 031003. https://doi.org/10.1115/1.3124088

9. Insperger T, Stépán G (2002) Semi-discretization method for delayed systems. Int J Numer Meth Eng 55(5): 503-518. https://doi.org/10.1002/nme.505

10. Insperger T, Stépán G (2004) Updated semi-discretization method for periodic delay-differential equations with discrete delay. Int $J$ Numer Meth Eng 61(1): 117-141. https://doi.org/10.1002/nme.1061

11. Insperger T, Stépán G, Turi J (2008) On the higher-order semi-discretizations for periodic delayed systems. J Sound Vib 313(1-2): 334-341. https://doi.org/10.1016/j.jsv.2007.11.040

12. Ding Y, Zhu LM, Zhang XJ, Ding H (2010) A full-discretization method for prediction of milling stability. Int J Mach Tools Manuf 50(5):502-509.

https://doi.org/10.1016/j.ijmachtools.2010.01.003

13. Ding Y, Zhu LM, Zhang XJ, Ding H (2010) Second-order full-discretization method for milling stability prediction. Int $\mathrm{J}$ Mach Tools Manuf 50 (10): 926-932. https://doi.org/10.1016/j.ijmachtools.2010.05.005

14. Guo Q, Sun YW, Jiang Y (2012) On the accurate calculation of milling stability limits using third-order full-discretization method. Int $\mathrm{J}$ Mach Tools Manuf 62: 61-66. https://doi.org/10.1016/j.ijmachtools.2012.07.008

15. Ozoegwu CG, Omenyi SN, Ofochebe SM (2015) Hyper-third order full-discretization methods in milling stability prediction. Int $J$ Mach Tools Manuf 92: 1-9. https://doi.org/10.1016/j.ijmachtools.2015.02.007

16. Liu YL, Zhang DH, Wu BH (2012) An efficient full-discretization method for prediction of milling stability. Int J Mach Tools Manuf 63: 44-48. doi: 10.1016/j.jimachtools.2012.07.008

17. Ozoegwu CG (2014) Least squares approximated stability boundaries of milling process. Int J Mach Tools Manuf 79: 24-30. https://doi.org/10.1016/j.ijmachtools.2014.02.001

18. Tang XW, Peng FY, Yan R, Gong YH, Li YT, Jiang LL (2016) Accurate and efficient prediction of milling stability with updated full-discretization method. Int J Adv Manuf Technol 88(9-12): 2357-2368. https://doi.org/10.1007/s00170-016-8923-7 
19. Yan ZH, Wang XB, Liu ZB, Wang DQ, Jiao L, Ji YJ (2017) Third-order updated full-discretization method for milling stability prediction. Int J Adv Manuf Technol 92(5-8): 2299-2309. https://doi.org/10.1007/s00170-017-0243-z

20. Zhou K, Feng P, Xu C, Zhang J, Wu Z (2017) High-order full-discretization methods for milling stability prediction by interpolating the delay term of time-delayed differential equations. Int $\mathrm{J}$ Adv Manuf Technol 93(5-8): 2201-2214. https://doi.org/10.1007/s00170-017-0692-4

21. Ji YJ, Wang XB, Liu ZB, Wang HJ, Yan ZH (2018) An updated full-discretization milling stability prediction method based on the higher-order Hermite-Newton interpolation polynomial. Int J Adv Manuf Technol 95(5-8):2227-2242. https://doi.org/10.1007/s00170-017-1409-4Y.

22. Dai YB, Li H, Hao B (2018) An improved full-discretization method for chatter stability prediction. Int J Adv Manuf Technol 96(9-12): 3503-3510.

https://doi.org/10.1007/s00170-018-1767-6

23. Qin C, Tao J, Liu C. (2019) A novel stability prediction method for milling operations using the holistic-interpolation scheme. P I Mech Eng C-J Mec 233(13), 4463-4475. https://doi.org/10.1177/0954406218815716

24. Ozoegwu CG, Eberhard P (2019) Tensor-Based Automatic Arbitrary Order Computation of the Full-Discretization Method for Milling Stability Analysis. In: Altenbach H., Irschik H., Matveenko V. (eds) Contributions to Advanced Dynamics and Continuum Mechanics. Advanced Structured Materials, vol 114, pp. 179-205. Springer, Cham. https://doi.org/10.1007/978-3-030-21251-3_11

25. Wu Y, You YP, Jiang JJ (2020) New predictor-corrector methods based on piecewise polynomial interpolation for milling stability prediction. Mach Sci Technol 24(5): 688-718. https://doi.org/10.1080/10910344.2020.1752235

26. Yang WA, Huang C, Cai X, You Y (2020) Effective and fast prediction of milling stability using a precise integration-based third-order full-discretization method. Int J Adv Manuf Technol 106(9), 4477-4498. https://doi.org/10.1007/s00170-019-04790-z

27. Yan ZH., Zhang CF, Jiang XG, Ma BJ (2020) Chatter stability analysis for milling with single-delay and multi-delay using combined high-order full-discretization method. Int J Adv Manuf Technol 111(9), 1401-1413. https://doi.org/10.1007/s00170-020-06147-3

28. Jiang S, Sun Y (2018) A multi-order method for predicting stability of a multi-delay milling system considering helix angle and run-out effects. Chinese J Aeronaut, 31(6): 1375-1387. https://doi.org/10.1016/j.cja.2017.08.005

29. Jiang S, Sun Y, Yuan X, Liu W (2017) A second-order semi-discretization method for the efficient and accurate stability prediction of milling process. The Int J Adv Manuf Technol 92(1-4): 583-595. https://doi.org/10.1007/s00170-017-0171-y

30. Liu KN, Zhang Y, Gao XY, Yang WX, Sun W, Dai F (2021) Improved semi-discretization method based on predictor-corrector scheme for milling stability analysis. The Int J Adv Manuf Technol 114: 3377-3389. https://doi.org/10.1007/s00170-021-06747-7

31. Ding Y, Zhu LM, Zhang XJ, Ding H (2011) Numerical Integration Method for Prediction of Milling Stability. J. Manuf. Sci. Eng 133(3): 031005. https://doi.org/10.1115/1.4004136

32. Dong X, Qiu Z (2020). Stability analysis in milling process based on updated numerical integration method. Mech Syst Signal Pr 106435. https://doi.org/10.1016/j.ymssp.2019.106435

33. Li MZ, Zhang G, Huang Y (2013) Complete discretization scheme for milling stability prediction. 
Nonlinear Dynam 71:187-199. https://doi.org/10.1007/s11071-012-0651-4

34. Xie QZ (2016) Milling stability prediction using an improved complete discretization method. Int J Adv Manuf Technol 83(5-8):815-821. https://doi.org/10.1007/s00170-015-7626-9

35. Niu JB, Ding Y, Zhu LM, Ding H (2014) Runge-Kutta methods for a semi-analytical prediction of milling stability. Nonlinear Dynam 76(1): 289-304. https://doi.org/10.1007/s11071-013-1127-x

36. Li ZQ, Yang ZK, Peng YR, Zhu F, and Ming XZ (2016) Prediction of chatter stability for milling process using Runge-Kutta-based complete discretization method. Int J Adv Manuf Technol 86(1): 943-952. https://doi.org/10.1007/s00170-015-8207-7

37. Dai YB, Li HK, Xing XY, Hao BT (2018) Prediction of chatter stability for milling process using precise integration method. Precis Eng 52: 152-157. https://doi.org/10.1016/j.precisioneng.2017.12.003

38. Ding Y, Zhu LM, Zhang XJ, Ding H (2013) Stability analysis of milling via the differential quadrature method. J Manuf Sci E-T ASME 135(4): 044502. https://doi.org/10.1115/1.4024539

39. Zhang XJ, Xiong CH, Ding Y, Ding H (2017) Prediction of chatter stability in high speed milling using the numerical differentiation method. Int J Adv Manuf Technol 89(9-12): 2535-2544. https://doi.org/10.1007/s00170-016-8708-z

40. Qin CJ, Tao JF, Shi HT, Xiao DY, Li BC, Liu CL (2020) A novel Chebyshev-wavelet-based approach for accurate and fast prediction of milling stability, Precis Eng 62: 244-255. https://doi.org/10.1016/j.precisioneng.2019.11.016

41. Qin CJ, Tao JF, Li L, Liu CL (2017) An Adams-Moulton-based method for stability prediction of milling processes. Int J Adv Manuf Technol 89(9-12): 3049-3058. https://doi.org/10.1007/s00170-016-9293-x

42. Qin CJ, Tao JF, Liu CL (2017) Stability analysis for milling operations using an Adams-Simpson-based method. Int J Adv Manuf Technol 92: 969-979. https://doi.org/10.1007/s00170-017-0186-4

43. Zhang Z, Li HG, Meng G, Liu C (2015) A novel approach for the prediction of the milling stability based on the Simpson method. Int $J$ Mach Tools Manuf 99: 43-47. https://doi.org/10.1016/j.ijmachtools.2015.09.002

44. Zhong WX, Williams FW (1994) A precise time step integration method. P I Mech Eng C-J Mec 208(6): 427-430. https://doi.org/10.1243/PIME_PROC_1994_208_148_02 